Vol.45, Special n. : pp. 135-142, September 2002 ISSN 1516-8913 Printed in Brazil

\title{
Technetium-99m Nitrido Radiopharmaceuticals Unprecedented Biological Properties
}

\author{
Adriano Duatti*; Alessandra Boschi and Licia Uccelli \\ Laboratory of Nuclear Medicine; Department of Clinical \& Experimental Medicine; University of Ferrara; Via L. \\ Borsari, 46; 44100 Ferrara - Italy; dta@unife.it
}

\begin{abstract}
The chemical methods for the production of technetium-99m radiopharmaceuticals containing a terminal Tc=N triple bond have been established more than a decade ago. From that time, the chemistry of nitrido Tc-99m complexes has provided a highly efficient tool for the design and preparation of novel classes of diagnostic agents, and a number of potentially useful radiopharmaceuticals have been discovered. In particular, nitrido technetium$99 m$ tracers have been developed for heart perfusion imaging. In this short review, the chemical and biological properties of the neutral myocardial perfusion tracer bis(N-ethoxy, N-ethyl-dithiocarbamato) nitrido Tc-99m (TcNNOEt) will be summarized along with the preparation and preliminary biological evaluation of the first class of monocationic nitrido technetium-99m radiopharmaceuticals exhibiting improved biodistribution properties closer to those expected for an ideal perfusion imaging agent.
\end{abstract}

Key words: Technetium-99m Radiopharmaceuticals, Nitrido Complexes

\section{INTRODUCTION}

Technetium-99m complexes containing a terminal $\mathrm{Tc} \equiv \mathrm{N}$ multiple bond are currently easily produced, at tracer level and in strictly controlled conditions, after the advent of improved chemical methods for obtaining the $\left[{ }^{99 m} \mathrm{Tc} \equiv \mathrm{N}\right]^{2+}$ core in high radiochemical purity (Duatti et al., 1988; Duatti and Uccelli, 1996; Pasqualini et al., 1990). A key advantage of using this type of complexes for obtaining novel classes of dia gnostic agents comes from their intrinsic structural robustness. Generally, nitrido Tc-99m complexes possess a five-coordinated arrangement, and geometry can switch from square pyramidal to trigonal bipyramidal. Through a careful selection of coordinated donor atoms, it is always possible to achieve a precise control of the geometrical features of the resulting complexes. This app ears to be of utmost importance in establishing structure-activity relationships to elucidate the biological behavior of this category of radiopharmaceuticals. The application of $\mathrm{n}$ itrido chemistry to the design of a broad range of radiopharmaceuticals, and specifically for the development of unprecedented categories of heart imaging agents is briefly reviewed here.

\section{${ }^{99 m}$ TeN-NOEt (CisNoet ${ }^{\text {TM}}$ )}

Bis-(N-ethoxy, N-ethyl-dithiocarbamato) nitrido technetium(V) or ${ }^{99 \mathrm{~m}} \mathrm{TcN}-\mathrm{NOEt}$ is a new technetium-99m labeled myocardial perfusion imaging agent which is currently undergoing

\footnotetext{
${ }^{*}$ Author for correspondence
} 
advanced phase III clinical evaluation (Pasqualini and Duatti, 1992; Fagret et al., 2001). The biological characteristics of ${ }^{99 \mathrm{~m}} \mathrm{TcN}-\mathrm{NOEt}$ are very interesting and different from those of the other myocardial perfusion radiopharmaceuticals.

Like ${ }^{99 \mathrm{~m}} \mathrm{Tc}$-teboroxime (and contrary to the other technetium-99m labeled agents) ${ }^{99 \mathrm{~m}} \mathrm{TcN}-\mathrm{NOEt}$ is a neutral technetium-99m complex. However, in contrast to ${ }^{99 \mathrm{~m}} \mathrm{Tc}$-teboroxime, ${ }^{99 \mathrm{~m}} \mathrm{TcN}-\mathrm{NOEt}$ is the first reported neutral technetium- $99 \mathrm{~m}$ complex showing long retention times in normal myocardial tissue. Furthermore, unlike ${ }^{99 \mathrm{~m}} \mathrm{Tc}$-sestamibi and ${ }^{99 \mathrm{~m}} \mathrm{Tc}$-tetrofosmin, ${ }^{99 \mathrm{~m}} \mathrm{TcN}-\mathrm{NOEt}$ shows a significant, myocardial redistribution over time. Therefore, ${ }^{99 \mathrm{~m}} \mathrm{TcN}-\mathrm{NOEt}$ is the first technetium-99m labeled myocardial perfusion agent that demonstrates similar characteristics than those of tha llium-201.

${ }^{99 \mathrm{~m}} \mathrm{TcN}-\mathrm{NOEt}$ is a member of a class of neutral myocardial imaging agents named ${ }^{99 \mathrm{~m}} \mathrm{Tc}$-nitrido dithiocarbamates which are characterized by the presence of a terminal triple-bond core $[\mathrm{Tc} \equiv \mathrm{N}]^{2+}$. It is a neutral and highly lipophilic compound with a octanol/water partition coefficient of approximately 3100 .

The preparation of ${ }^{99 \mathrm{~m}} \mathrm{TcN}-\mathrm{NOEt}$ is carried out through a two-vial lyophilized kit formulation supplied by CIS-Schering. ${ }^{99 \mathrm{~m}} \mathrm{Tc}$-pertechnetate (500-1800 Mbq) is added to a first vial containing the following components in a freeze-dried form:

(i) $5.0 \mathrm{mg} \mathrm{SDH}$ (succinic dihydrazide),

(ii) $0.08 \mathrm{mg} \mathrm{SnCl} 1_{2} \cdot 2 \mathrm{H}_{2} \mathrm{O}$,

(iii) $5.0 \mathrm{mg}$ DTPA (1,2-propane-N,N,N',N'-tetraacetic acid).

The resultant mixture is kept at room temper ature for 15 minutes. Then, $10 \mathrm{mg}$ of the sodium salt of $\mathrm{N}$-ethoxy, N-ethyl dithiocarbamate and $10 \mathrm{mg}$ of $\beta$-methyl-cyclodextrin (which serves as a surfactant and solubilizing agent) dissolved in 1.0 $\mathrm{ml}$ of water are withdrawn from the second vial and added to the first reaction vial. The final solution stands for 5 minutes at room te mperature. Comparison between myocardial distribution of ${ }^{99 \mathrm{~m}} \mathrm{TcN}-\mathrm{NOEt}$ and regional myocardial blood flow has been performed in dogs after permanent and temporary partial coronary occlusion of the left anterior descending artery and dipyridamole infusion. The first-pass extraction fraction of ${ }^{99 \mathrm{~m}} \mathrm{TcN}-\mathrm{NOEt}$ was $75 \pm 4$ under basal conditions and $85 \pm 2 \%$ under hyperemic conditions. This high extraction fraction is similar to that of ${ }^{99 \mathrm{~m}}$ Tc-teboroxime. The lipophilic properties explain the high extraction fraction of both radiopharmaceuticals. Another study showed that the mean ${ }^{99 \mathrm{~m}} \mathrm{TcN}-\mathrm{NOEt}$ extraction fraction was 87 \pm 1 (range: $81-90 \%$ ) at normal coronary flow rate and $82 \pm 1$ with adenosine infusion. This extraction fraction is similar to the one reported for thallium-201 using a similar experimental model.

Despite the persistent significant linear correl ation between ${ }^{99 m} \mathrm{TcN}-\mathrm{NOEt}$ activity and regional myocardial blood flow during 90 minutes after the injection, when partial coronary occlusion was maintained, there was an increase in my ocardial ${ }^{99 \mathrm{~m}} \mathrm{TcN}-\mathrm{NOEt}$ activity relative to the blood flow as measured by microspheres in the $0-20$ flow range and a decrease in the 80-100 flow range. These data suggest a continuous and slow myocardial redistribution of ${ }^{99 \mathrm{~m}} \mathrm{TcN}-\mathrm{NOEt}$ 15-90 minutes after the injection. Some of the data also showed that there was an early myocardial redistribution of ${ }^{99 \mathrm{~m}} \mathrm{TcN}-\mathrm{NOEt}$ within the first 15 minutes following its administration.

The blood clearance of ${ }^{99 \mathrm{~m}} \mathrm{TcN}-\mathrm{NOEt}$ was biexponential with an initial half-life of 4.7 minutes and a late half-life of 674 minutes. No metabolite of ${ }^{99 \mathrm{~m}} \mathrm{TcN}-\mathrm{NOEt}$ has been detected in the blood at 2 or 60 minutes post-injection. In vivo imaging in animal models showed that the myocardial uptake of ${ }^{99 \mathrm{~m}} \mathrm{TcN}-\mathrm{NOEt}$ at 60 minutes post injection had decreased by $43 \%$ to that measured at 5 minutes. The lung uptake was initially high but decreased faster than cardiac uptake with a heart-to-lung ratio of 1.04 at 5 minutes and 1.84 at 60 minutes post injection. The liver uptake remained constant over time. Five minutes after the injection, the in vitro ${ }^{99 \mathrm{~m}} \mathrm{TcN}-\mathrm{NOEt}$ uptake was higher than thallium201 over a wide range of flow. Although myocardial uptake of both agents underestimated the level of flow disparity, ${ }^{99 \mathrm{~m}} \mathrm{TcN}-\mathrm{NOEt}$ uptake more closely matched coronary blood flow than did thallium-201. It was concluded that ${ }^{99 \mathrm{~m}} \mathrm{TcN}-\mathrm{NOEt}$ is the first technetiurn-99m labeled myocardial perfusion imaging agent with cardiac retention higher than that of thallium-201 at 5 minutes post-injection.

The subcellular distribution of ${ }^{99 \mathrm{~m}} \mathrm{TcN}-\mathrm{NOEt}$ was determined in Sprague-Dawley rat hearts using standard differential centrifugation tec hniques. It was found that ${ }^{99 \mathrm{~m}} \mathrm{TcN}-\mathrm{NOEt}$ can diffuse and localize in the hydrophobic components of 
myocardial cells with no evidence of specific association of activity with the mitochondrial and cytosolic components. Structural membrane integrity was found to be important in the myocardial retention of ${ }^{99 \mathrm{~m}} \mathrm{TcN}-\mathrm{NOEt}$. After induction of severe cell membrane and organelle disruption, there was no release of ${ }^{99 \mathrm{~m}} \mathrm{TcN}-\mathrm{NOEt}$ activity in the cytosol. These observations strongly support the hypothesis that ${ }^{99 \mathrm{~m}} \mathrm{TcN}-\mathrm{NOEt}$, a neutral and lipophilic radiotracer, remains tightly bound to the hydrophobic components of the cell, and that the cell membranes are the most probable subcellular location site of ${ }^{99 \mathrm{~m}} \mathrm{TcN}-\mathrm{NOEt}$.

In vitro experiments and studies performed in animals and in humans have demonstrated myocardial redistribution of ${ }^{99 \mathrm{~m}} \mathrm{TcN}-\mathrm{NOEt}$ with a similar behavior than that of thallium-201. In dogs myocardial uptake of ${ }^{99 \mathrm{~m}} \mathrm{TcN}-\mathrm{NOEt}$ and thallium201 were determined by in vitro counting and correlated with radiolabelled microspheres data. Results clearly demonstrated that ${ }^{99 \mathrm{~m}} \mathrm{TcN}-\mathrm{NOEt}$ myocardial redistribution was comp arable to that of thallium-201.

Biodistribution of ${ }^{99 \mathrm{~m}} \mathrm{TcN}-\mathrm{NOEt}$ in man has showed that the myocardial uptake of ${ }^{99 \mathrm{~m}} \mathrm{TcN}-\mathrm{NOEt}$ is rapid, high and stable in time, and it is rapidly cleared from the circulating blood. Although the myocardial uptake of ${ }^{99 \mathrm{~m}} \mathrm{TcN}-\mathrm{NOEt}$ is higher than the uptake of other technetium $-99 \mathrm{~m}$ labeled myocardial perfusion imaging agents, the lung uptake is also higher with approximately $20 \%$ of the injected dose in the lungs 5 minutes after the injection at rest with a lung half-life of 50 minutes at rest and 77 minutes at stress. Liver uptake was $21 \%$ of injected dose at 30 minutes, $27 \%$ at 2 hours and 20\%\%at 4 hours. The myocardial uptake was $5.2 \%$ of the injected dose at 30 minutes and $4.8 \%$ at 4 hours.

\section{${ }^{99}{ }^{9}$ Tc-NITRIDO HETEROCOMPLEXES}

The search for stable coordination arrangements including technetium. in various oxidation states continues to be an active field of research, particularly because of the prominent role still played by the $\gamma$-emitting radionuclide technetium-99m in diagnostic nuclear medicine. This effort has recently received further impulse owing to the current needs to develop Tc-99m radiopharmaceuticals for monitoring receptor distributions in the central nervous system and in various tissues.
In the last years, two main approaches to the design of Tc-99m receptor imaging agents have been proposed. Both strategies set forth to start initially with the selection of a suitable biologically active molecule or d rug that is already know to have affinity for a specific receptor, and thus could serve as a guide for picturing the structure of the final Tc-99m receptor radiopharmaceutical. After this common input, the two methods diverge. The so-called 'bifunctional' or 'pendant' approach literally suggests to append the bioactive group to a metal complex through a suitable linkage. This can be conveniently accomplished by using a 'bifunctional ligand' that could be viewed as a composite molecule combining a strong chelating group for the radiometal with the biomolecule by means of a suitable linker connecting these two moieties. After the radiometal has been encaged by the chelating system, the resulting 'conjugate' complex will retain the bioactive group into its structure as an appended side chain. Instead, the other procedure, called 'integrated approach', puts its focus on the selected biomolecule itself with the aim to identify a region in its structure that is not essential for preserving its biological properties such as, for example, its affinity for a receptor. On this ground, the final radiopharmaceutical is assembled by replacing the non-essential part of the biomolecule with a metal containing fragment, which should have molecular shape similar to that of the substituted portion so as to fit almost exactly into the same position in the original biomolecule. Obviously, the ultimate success of both design strategies lies in their ability to keep unaltered the intrinsic biological behavior of the starting biomolecule.

A key, theoretical advantage of the two approaches outlined above originates from their representation of the molecular structure of the radioactive tracer as consisting of different 'pieces' or 'fragments', which can be, at least in principle, conveniently assembled to build up the final radiopharmaceutical. However, the merging of the various fragments to yield a st able product is not always simple to accomplish and, for practical purposes, this has been act ually obtained only through the application of the bifunctional approach to a few, selected chelating sy stems for the metal.

Since the $\left[{ }^{99 m} \mathrm{Tc} \equiv \mathrm{N}\right]^{2+}$ core can be viewed as a true inorganic functional group exhibiting a very high stability over a wide range of experimental 
conditions, it was of importance to investigate the possibility of employing the chemistry of nitrido $\mathrm{Tc}(\mathrm{V})$ complexes for labeling bioactive molecules. Generally, complexes containing the $\mathrm{Tc} \equiv \mathrm{N}$ triple bond are characterized by a five-coordination arrangement of ligands determined by the strong trans-weakening exerted by the nitrido nitrogen group $\left(\mathrm{N}^{3-}\right)$. Therefore, a plain strategy for linking a bioactive molecule to a $\left[{ }^{99 m} \mathrm{Tc} \equiv \mathrm{N}\right]^{2+}$ core would require the design of a bifunctional ligand combining a tetradentate chelating system with the biological substrate. The metal ion could be, then, coordinated to the tetradentate chelating framework to afford the final conjugated complex. Though the outlined approach has been successfully applied to the isoelectronic $\left[\mathrm{Tc}^{\mathrm{V}}=\mathrm{O}\right]^{3+}$ core, previous studies demonstrated that coordination of a tetradentate ligand to a $\mathrm{Tc} \equiv \mathrm{N}$ group is less favored than that of two separate bidentate ligands, presumably as a result of heavy sterical constrains imparted by the more demanding nitrido group. Hence, a further possibility to include a biologically active molecule into a nitrido $\mathrm{Tc}(\mathrm{V})$ complex is offered by the formation of a disubstituted co mplex with two bidentate ligands. However, based on the biological requirement that only a single bioactive group has to be retained into the structure of the final complex to avoid strong alterations of the properties of the original bi omolecule, it comes out that these two bidentate ligands should be necessarily different. In particular, this approach requires that the final heterocomplex must be composed of a $\left.\left[{ }^{99 \mathrm{~m}} \mathrm{Tc} \equiv \mathrm{N}\right]\right]^{2+}$ core bound to a single bifunctional bidentate ligand carrying the bioactive group, and another ancillary ligand spanning the remaining two coordination positions of a five-coordination arrangement. Yet, the poss ibility of obtaining pure asymmetrical heteroco mplexes when two different bidentate ligands are reacted with a $\left[{ }^{99 \mathrm{~m}} \mathrm{Tc} \equiv \mathrm{N}\right]^{2+}$ core group is not commonplace. For instance, when the size of the biomolecule is sufficiently small, it is obvious that coordination of two identical bifunctional ligands to the same $\mathrm{Tc}(\mathrm{V})$ center has to be expected. Previous attempts to obtain analogous disubstituted heterocomplexes with the isoelectronic $\left.\left[\mathrm{Tc}^{\mathrm{V}}=\mathrm{O}\right)\right]^{3+}$ core gave only poor results with production of unstable species in dynamic equilibrium with the corresponding symmetrical compounds composed of two identical bidentate ligands.
A detailed investigation of the relationships occurring between the various geometries of five-coordinated nitrido $\mathrm{Tc}(\mathrm{V})$ complexes and the nature of the set of donor atoms bound to the metal center allowed an efficient procedure to be devised for the selective preparation of stable asymmetrical heterocomplexes. In a previous work, we reported the synthesis of disubstituted nitrido $\mathrm{Tc}(\mathrm{V})$ complexes with phosphinethiol ligands $(\mathrm{PSH})$ of the type $\left[\mathrm{Tc}(\mathrm{N})(\mathrm{PS})_{2}\right]$. The structural characterization of these complexes showed that they possess a trigonal-bipyramidal geometry where the two phosphorus atoms o ccupy the two apical sites, and the two sulfur atoms and the nitrido nitrogen atom are located on the equatorial plane. This type of geometry is uncommon for nitrido $\mathrm{Tc}(\mathrm{V})$ co mplexes, and never occurs with ligands having $\pi$-donors as coordinating atoms. In this latter situ ation, square pyramidal geometry is preferred. We attributed these structural features to the strong preference of $\pi$-acceptor phosphorus atoms to achieve a reciprocal trans position as opposed to $\pi$-donor atoms which tend to assume a cis a rrangement. PSH ligands were found to be very powerful coordinating agents toward the $\left[{ }^{99 \mathrm{~m}} \mathrm{Tc} \equiv \mathrm{N}\right]^{2+}$ core. In square-pyramidal complexes, $\pi$-donor substituents were quantitatively removed by these ligands to yield the same $\left[\mathrm{Tc}(\mathrm{N})(\mathrm{PS})_{2}\right]$ complexes. Thus, it may be concluded that a $\mathrm{P}_{2} \mathrm{~S}_{2}$ arrangement of atoms, coordinated to a $\left[{ }^{99 \mathrm{~m}} \mathrm{Tc} \equiv \mathrm{N}\right]^{2+}$ group in a trigonal bipyramidal geometry, should be highly stable. Even though a nitrido $\mathrm{Tc}(\mathrm{V})$ complex with two bidentate ligands hardly would achieve a full trigonal bipyramidal structure, this conclusion can be generalized to include all se ts of two $\pi$-acceptor and two $\pi$-donor atoms.

In $\left[\mathrm{Tc}(\mathrm{N})(\mathrm{PS})_{2}\right]$ complexes, the $\mathrm{P}$ and $\mathrm{S}$ atoms of the phosphinethiol ligands are joined together through an alkyl bridge. Thus, based on our above arguments, we speculated that by changing the connectivity between $\mathrm{P}$ and $\mathrm{S}$ atoms, it would be possible to produce asymmetrical complexes having a stability similar to that of the precursor compounds. Specifically, by linking separately the two $\mathrm{P}$ atoms and the two $\mathrm{S}$ atoms, the resulting heterocomplex $[\mathrm{Tc}(\mathrm{N})(\mathrm{P}-\mathrm{P})(\mathrm{S}-\mathrm{S})]$ would be composed by a diphosphine ligand (P-P) and a bidentate dithiol ligand (S-S) coordinated to a ${ }^{99 \mathrm{~m}} \mathrm{Tc} \equiv \mathrm{N}$ group. A far-reaching consequence of this conjecture implies that a highly acidic molecular fragment of the type $[\mathrm{Tc}(\mathrm{N})(\mathrm{P}-\mathrm{P})]^{2+}$ 
formed by a $\left[{ }^{99 \mathrm{~m}} \mathrm{Tc} \equiv \mathrm{N}\right]^{2+}$ core bound to a diphosphine ligand, should exhibit a selective reactivity toward nucleophilic bidentate ligands (YZ) having $\pi$-donors as coordinating atoms. This leads to the prediction that there should exist a synthetic route to the selective preparation of the heterocomplexes $[\mathrm{Tc}(\mathrm{N})(\mathrm{P}-\mathrm{P})(\mathrm{YZ})]$ through the reaction of the ligands $\mathrm{P}-\mathrm{P}$ and $\mathrm{YZ}$ with a nitrido $\mathrm{Tc}(\mathrm{V})$ precursor, without the concomitant formation of the corresponding symmetrical species. In these reactions, the arrangement of atoms $\left[{ }^{99 \mathrm{~m}} \mathrm{Tc}(\mathrm{N})(\mathrm{P}-\mathrm{P})\right]^{2+}$, composed by a $\mathrm{Tc} \equiv \mathrm{N}$ group coordinated to a chelating diphosphine ligand P-P, behaves as 'robust' metal fragment, interacting with the incoming $\pi$-donor $\mathrm{YZ}$ ligand to afford the asymmetrical complex $\left[{ }^{99 \mathrm{~m}} \mathrm{Tc}(\mathrm{N})(\mathrm{P}-\right.$ $\mathrm{P})(\mathrm{YZ})]^{0 /+}$. Thus, the metal synthon $\left[{ }^{99 \mathrm{~m}} \mathrm{Tc}(\mathrm{N})(\mathrm{P}-\right.$ $\mathrm{P})]^{2+}$ could be conveniently utilized to obtain a very broad class of asymmetrical nitrido $\mathrm{Tc}(\mathrm{V})$ complexes with a variety of bidentate ligands (Bolzati et al., 2000, 2001).

Using the chemical strategy outline above, a novel class of Tc-99m heart imaging agents was discovered. These compounds possess the u nusual asymmetrical structure of nitrido heter ocomplexes composed by a diphosphine ligand (P-P) and a dithiocarbamate ligand (L) bound to the same $[\mathrm{Tc} \equiv \mathrm{N}]^{2+}$ group (Boschi et al., 2002). The resulting complexes, $\left[{ }^{99 \mathrm{~m}} \mathrm{Tc}(\mathrm{N})(\mathrm{P}-\mathrm{P})(\mathrm{L})\right]^{+}$, are monocationic and biodistribution studies in rats revealed that these new tracers were sele ctively extracted by the myocardium and exhibited a biological behavior closer to that of an ideal perfusion agent. In particular, the diphosphine ligands PNP3 and PNP5, and the dithi ocarbamate ligand DBODC illustrated in Figure 1 were used.

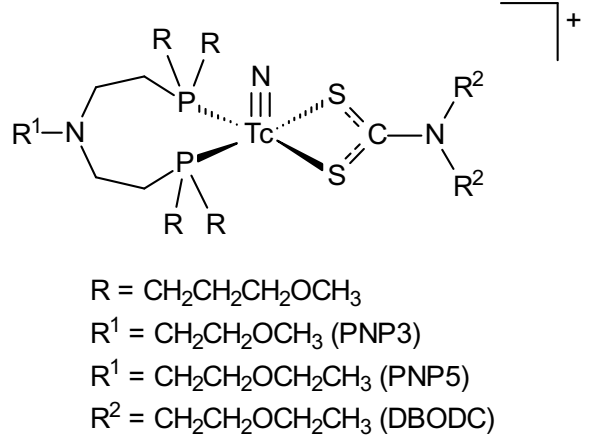

Figure 1 - Chemical structure of asymmetrical nitrido Tc-99m heterocomplexes
A schematic drawing of the struc ture of the novel complexes $\quad\left[{ }^{99 \mathrm{~m}} \mathrm{Tc}(\mathrm{N})(\mathrm{PNP})(\mathrm{DBODC})\right]^{+}$ (abbreviated ${ }^{99 \mathrm{~m}} \mathrm{TcN}-\mathrm{DBODC} 3$ when P-P $=$ PNP3, and ${ }^{99 \mathrm{~m}}$ TcN-DBODC5 when P-P = PNP5) is reported in Figure 1. The complexes are monocationic and possess a distorted squarepyramidal structure with an apical $\mathrm{Tc} \equiv \mathrm{N}$ bond and the ligands P-P and DBODC spanning the residual four positions on the basal plane.

Biodistribution studies for the two complexes ${ }^{99 \mathrm{~m}} \mathrm{TcN}-\mathrm{DBODC} 3$ and ${ }^{99 \mathrm{~m}} \mathrm{TcN}-\mathrm{DBODC} 5$ were performed in rats (Table 1).

The complexes were rapidly extracted by the myocardium and retained in this region for a prolonged time. The main excretion routes were through the kidneys and the liver. However, liver activity washed out almost completely into the intestine after one hour post injection. Time variation of heart uptakes for the monocationic compounds ${ }^{99 \mathrm{~m}} \mathrm{TcN}-\mathrm{DBODC} 3,{ }^{99 \mathrm{~m}} \mathrm{TcN}-D B O D C 5$, ${ }^{99 \mathrm{~m}} \mathrm{Tc}$-Sestamibi and ${ }^{99 \mathrm{~m}} \mathrm{Tc}-$ Tetrofosmin are reported in Figure 2. Comparisons between heart/lung and heart/liver uptake ratios for the same complexes are illustrated in Figures 3 and 4, respectively.

The novel Tc-99m complexes appear to possess remarkable biological properties. Both co mplexes ${ }^{99 \mathrm{~m}} \mathrm{TcN}-\mathrm{DBODC} 3$ and ${ }^{99 \mathrm{~m}} \mathrm{TcN}-D B O D C 5$ exhibited high heart localization. The vanishing lung accumulation observed after 2 min post injection, and fast liver washout suggested that there should exist a peak activity precisely loca lized in the heart region. As a consequence, cardiac images were expected to be particularly well-defined. This prediction was confirmed by collecting tomographic images of the rat heart using a smallanimal SPET scanner currently under development in our laboratory. Results are given in Figure 5. Remarkably, liver activity was practically absent. Analysis of time variation of heart/lung and heart/liver uptake ratios for ${ }^{99 \mathrm{~m}} \mathrm{TcN}-\mathrm{DBODC} 3$ and ${ }^{99 \mathrm{~m}} \mathrm{TcN}-\mathrm{DBODC} 5$ revealed dramatic differences between these monocationic asymme trical complexes and the monocationic complexes ${ }^{99 \mathrm{~m}} \mathrm{Tc}$ Sestamibi and ${ }^{99 \mathrm{~m}} \mathrm{Tc}-$ Tetrofosmin, as illustrated in Figures 3 and 4. Heart/lung ratios for ${ }^{99 \mathrm{~m}} \mathrm{TcN}$ DBODC3 and ${ }^{99 \mathrm{~m}} \mathrm{TcN}-\mathrm{DBODC5}$ increased continuosly in time. Similarly, heart/liver ratios grew exponentially and were found to be much superior than the same ratios measured for ${ }^{99 \mathrm{~m}} \mathrm{Tc}$ Sestamibi and ${ }^{99 \mathrm{~m}}$ Tc-Tetrofosmin. 
Table 1 - Organ distribution in rats of 99mTcN-DBODC3 (1) and 99mTcN-DBODC5 (2) (percentage dose/gram, average of three rats \pm SD)

\begin{tabular}{ccccccc}
\hline Organ & $0 \mathrm{~min}$ & $10 \mathrm{~min}$ & $30 \mathrm{~min}$ & $60 \mathrm{~min}$ & $120 \mathrm{~min}$ & $180 \mathrm{~min}$ \\
\hline Blood & $0.55 \pm 0.32$ & $0.03 \pm 0.00$ & $0.02 \pm 0.00$ & $0.01 \pm 0.00$ & $0.01 \pm 0.00$ & $0.01 \pm 0.00$ \\
Heart & $3.57 \pm 0.14$ & $3.65 \pm 0.56$ & $3.27 \pm 0.36$ & $3.27 \pm 0.62$ & $3.00 \pm 0.42$ & $3.13 \pm 0.05$ \\
Lungs & $1.54 \pm 0.03$ & $0.77 \pm 0.10$ & $0.69 \pm 0.12$ & $0.34 \pm 0.11$ & $0.27 \pm 0.05$ & $0.18 \pm 0.02$ \\
Liver & $1.46 \pm 0.05$ & $1.43 \pm 0.47$ & $0.42 \pm 0.01$ & $0.16 \pm 0.05$ & $0.12 \pm 0.03$ & $0.06 \pm 0.02$ \\
Kidneys & $10.40 \pm 2.16$ & $6.74 \pm 0.63$ & $5.67 \pm 0.39$ & $4.24 \pm 0.53$ & $3.48 \pm 0.61$ & $2.74 \pm 0.12$ \\
Intestine & $2.43 \pm 0.49$ & $12.11 \pm 2.92$ & $13.41 \pm 4.62$ & $4.39 \pm 2.86$ & $7.03 \pm 2.61$ & $5.44 \pm 1.09$ \\
Muscle & $0.23 \pm 0.04$ & $0.23 \pm 0.07$ & $0.24 \pm 0.08$ & $0.17 \pm 0.01$ & $0.36 \pm 0.15$ & $0.12 \pm 0.08$ \\
\hline Blood & $6.65 \pm 0.50$ & $0.03 \pm 0.01$ & $0.02 \pm 0.00$ & $0.01 \pm 0.00$ & $0.01 \pm 0.00$ & $0.00 \pm 0.00$ \\
Heart & $5.01 \pm 0.16$ & $3.69 \pm 0.29$ & $3.73 \pm 0.48$ & $3.76 \pm 0.39$ & $3.31 \pm 0.06$ & $3.38 \pm 0.04$ \\
Lungs & $6.58 \pm 1.09$ & $0.88 \pm 0.03$ & $0.64 \pm 0.13$ & $0.46 \pm 0.07$ & $0.25 \pm 0.01$ & $0.18 \pm 0.03$ \\
Liver & $0.82 \pm 0.09$ & $1.61 \pm 0.21$ & $0.72 \pm 0.06$ & $0.20 \pm 0.05$ & $0.10 \pm 0.03$ & $0.05 \pm 0.01$ \\
Kidneys & $3.71 \pm 2.38$ & $9.16 \pm 1.08$ & $6.70 \pm 0.98$ & $5.73 \pm 0.55$ & $3.48 \pm 0.14$ & $2.98 \pm 0.15$ \\
Intestine & $1.71 \pm 1.33$ & $9.04 \pm 1.71$ & $6.70 \pm 0.71$ & $6.52 \pm 7.65$ & $6.57 \pm 5.38$ & $5.88 \pm 3.64$ \\
Muscle & $0.09 \pm 0.11$ & $0.21 \pm 0.05$ & $0.19 \pm 0.04$ & $0.21 \pm 0.03$ & $0.23 \pm 0.06$ & $0.10 \pm 0.05$ \\
\hline & & & & & & \\
\hline
\end{tabular}

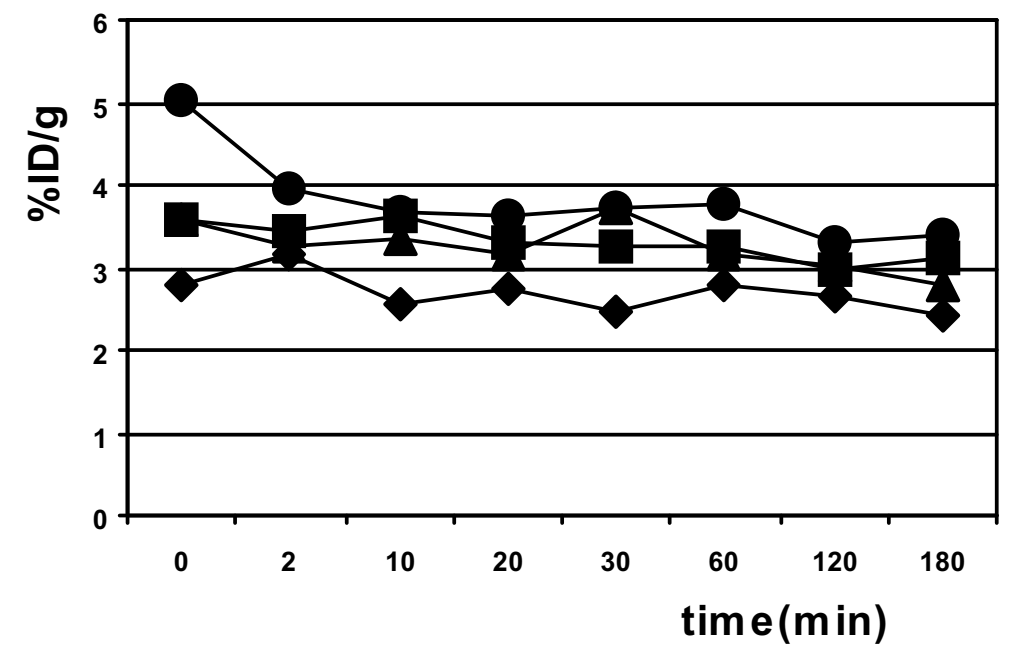

Figure 2 - Time-variation of heart uptake (percentage dose/organ, average of three rats, standard deviations are omitted for clarity) for ${ }^{99 \mathrm{~m}} \mathrm{Tc}-\mathrm{Sestamibi}(\boldsymbol{\Delta})$, ${ }^{99 \mathrm{~m}}$ Tc-Tetrofosmin $(\bullet),{ }^{99 \mathrm{~m}} \mathrm{TcN}-\mathrm{DBODC} 3(\boldsymbol{\bullet})$ and ${ }^{99 \mathrm{~m}} \mathrm{TcN}-\mathrm{DBODC} 5(\bullet)$ 


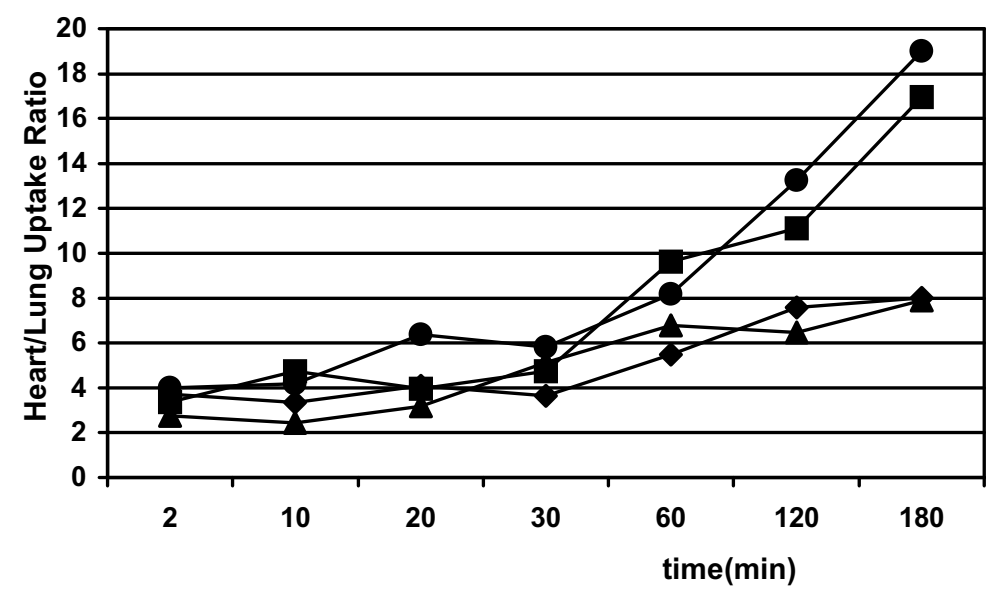

Figure 3 - Time-variation of heart/lung uptake ratio for ${ }^{99 \mathrm{~m}}$ Tc-Sestamibi $(\boldsymbol{\Delta})$, ${ }^{99 \mathrm{~m}}$ Tc-Tetrofosmin $(\bullet),{ }^{99 \mathrm{~m}} \mathrm{TcN}-D B O D C 3(\boldsymbol{\bullet})$ and ${ }^{99 \mathrm{~m}} \mathrm{TcN}-\mathrm{DBODC} 5(\bullet)$

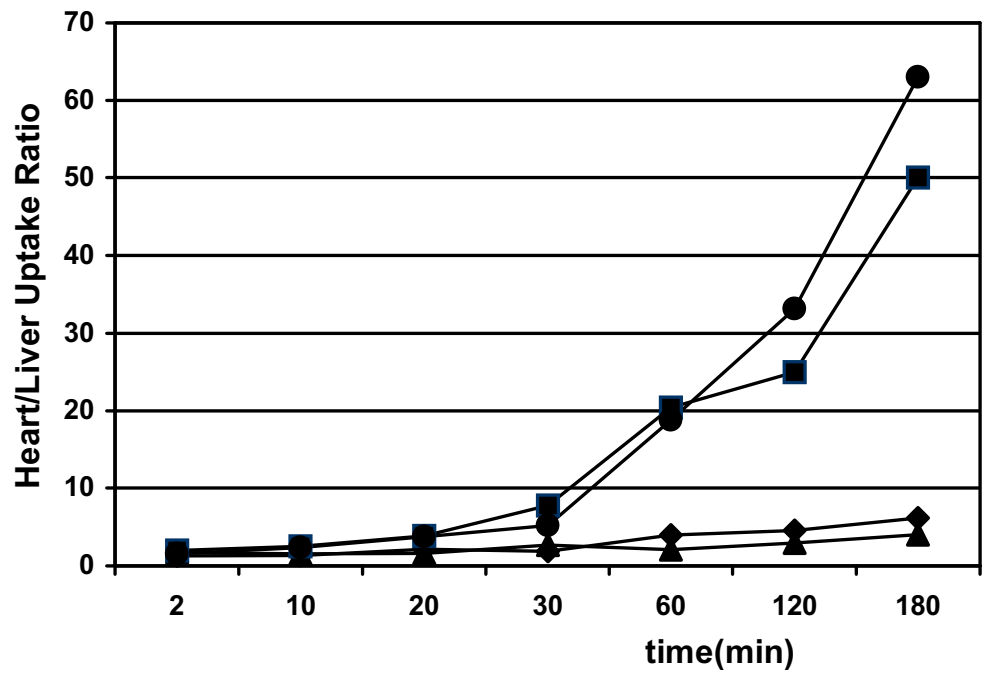

Figure 4 - Time-variation of heart/liver uptake ratio for ${ }^{99 \mathrm{~m}} \mathrm{Tc}-\mathrm{Sestamibi}(\boldsymbol{\Delta})$, ${ }^{99 \mathrm{~m}} \mathrm{Tc}$-Tetrofosmin $(\bullet),{ }^{99 \mathrm{~m}} \mathrm{TcN}-D B O D C 3(\boldsymbol{\bullet})$ and ${ }^{99 \mathrm{~m}} \mathrm{TcN}-D B O D C 5(\bullet)$

In conclusion, the novel complexes ${ }^{99 \mathrm{~m}} \mathrm{TcN}$ DBODC3 and ${ }^{99 \mathrm{~m}} \mathrm{TcN}-\mathrm{DBODC} 5$ appear to possess superior biological properties in comparison with ${ }^{99 \mathrm{~m}} \mathrm{Tc}$-Sestamibi and ${ }^{99 \mathrm{~m}} \mathrm{Tc}-$ Tetrofosmin, and could be potentially utilized as improved heart imaging agents for obtaining high-quality scintigraphic images. 


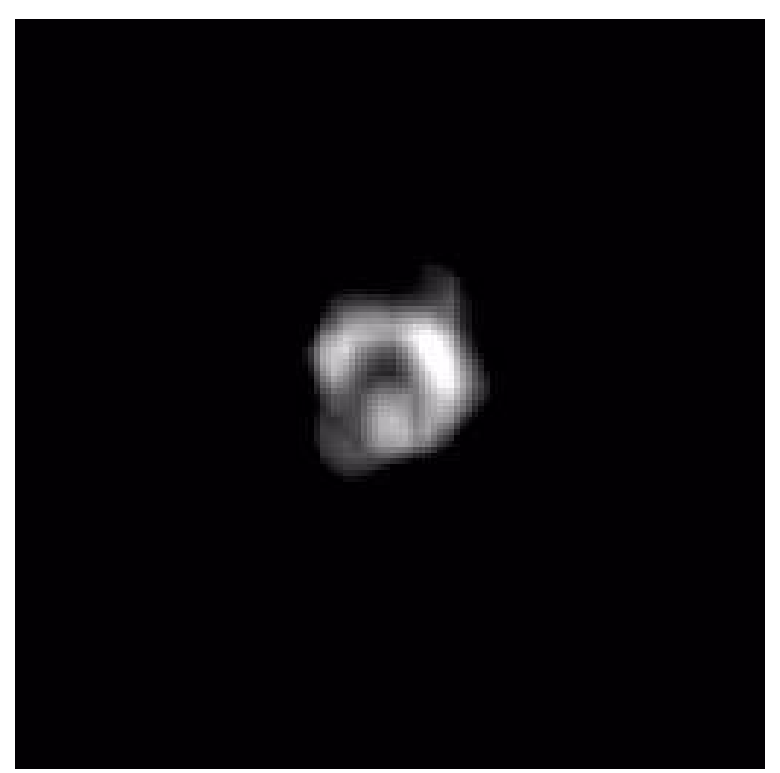

Figure 5 - Tomographic image of rat heart obtained 60 min post injection of ${ }^{99 \mathrm{~m}} \mathrm{TcN}-\mathrm{DBODC} 5$

\section{RESUMO}

Os métodos químicos para produção de radiofármacos marcados com tecnécio-99m contendo a ligação tripla terminal $\mathrm{Tc} \equiv \mathrm{N}$ foram estabelecidos há mais de uma década. Desde esta época, a química dos complexos nitridos marcados com ${ }^{99 m}$ Tc tem sido uma ferramenta altamente eficiente para o desenho e preparo de novas classes de agentes para diagnóstico e, foi descoberto um número de radiofarmacos potencialmente úteis. Nesta pequena revisão, as propriedades biológicas e químicas do traçador para perfusão miocárdica neutra, o bis(N-etoxi, Netil-ditiocarbamato) nitrido ${ }^{99 \mathrm{~m}} \mathrm{Tc}$ (TcN-NOEt), serão resumidas junto com o preparo e avaliação biológica preliminar da primeira classe de radiofármacos nitrido monocatiônico marcado com tecnécio-99m que exibe melhores propriedades em relação à biodistribuição, mais próximas daquelas esperadas para um agente perfusor ideal para imagens.

\section{REFERENCES}

Bolzati, C.; Boschi, A.; Duatti, A.; Prakash, S.; Uccelli, L.; Refosco, F.; Tisato, F. and Bandoli, G. (2000), Geometrically controlled selective formation of nitrido technetium(V) asymmetrical heterocomplexes with bidentate ligands. J. Am. Chem. Soc., 122, 4510-4511.

Boschi, A.; Bolzati, C.; Uccelli, L.; Duatti, A.; Benini, E.; Refosco, F.; Tisato, F. and Piffanelli, A. (2002), A class of asymmetrical nitrido technetium-99m complexes as heart imaging agents with improved biological properties. Nucl. Med. Commun. [in press].

Duatti, A.; Marchi, A. and Pasqualini, R. (1990), Formation of the $\mathrm{Tc} \equiv \mathrm{N}$ multiple bond from the reaction of ammonium pertechnetate with $S$-methyl dithiocarbazate and its application to the preparation of technetium-99m radiopharmaceuticals. J. Chem. Soc., Dalton Trans., 3729-3733.

Duatti, A. and Uccelli, L. (1996), Technetium complexes and radiopharmaceuticals containing the $\mathrm{Tc} \equiv \mathrm{N}$ multiple bond. Trends Inorg. Chem, 4, 27-41.

Fagret, D.; Ghezzi, C. and Vanzetto, G. (2001), ${ }^{99 \mathrm{~m}}$ TcN-NOET imaging for myocardial perfusion: can it offer more than we already have? J. Nucl. Med., 42, 1395-1396.

Pasqualini, R.; Comazzi, V.; Bellande, E.; Duatti, A. and Marchi, A. (1992), A new efficient method for the preparation of $99 \mathrm{~m}$ Tc-radiopharmaceuticals containing the $\mathrm{Tc} \equiv \mathrm{N}$ multiple bond. Appl. Radiat. Isot., 43, 1329-1333.

Pasqualini, R. and Duatti, A. (1992), Synthesis and characterization of the new neutral myocardial imaging agent $\left[{ }^{99 \mathrm{~m}} \mathrm{TcN}(\right.$ noet) 2$]$ (noet $=N$-ethyl- $N$ ethoxydithiocarbamato). J. Chem. Soc. Chem. Commun., 1354-1355. 